\title{
Tackling the Diagnosis: Solid Pseudopapillary Tumor of the Pancreas in a Young Man
}

\author{
Marilia Campos ${ }^{\mathrm{a}, \mathrm{e}}$, James Campbell ${ }^{\mathrm{b}}$, Hernando Gonzalez ${ }^{\mathrm{c}}$, \\ Mufaddal Najmuddin ${ }^{\mathrm{d}}$
}

\begin{abstract}
Solid pseudopapillary tumor (SPT) of the pancreas is an extremely rare pancreatic tumor. It usually goes undetectable for a prolonged period of time given its lack of clinical symptoms. But when detected, it has a malignancy potential of $15 \%$. Here we present a case of SPT diagnosed incidentally in a 17-year-old man during a routine evaluation for an abdominal trauma.
\end{abstract}

Keywords: Solid pseudopapillary tumor; Pancreatic tumor; Young man

\section{Introduction}

Solid pseudopapillary tumor (SPT) of the pancreas represents only about $1 \%$ of all pancreatic tumors. It is more common in women (10:1) and has a low malignancy potential of approximately $15 \%$. This case describes the incidental finding of an SPT in a healthy 17-year-old male patient.

\section{Case Report}

A 17-year-old otherwise healthy man presented for an abdominal trauma evaluation after being tackled at a football game. No major injuries were found.

During the evaluation, an incidental $5.8-\mathrm{cm}$ pancreatic mass was noted on contrast-enhanced abdominal computed tomography (CT) (Fig. 1). He denied any previous symptoms, including abdominal pain, mass and/or weight loss. Magnetic resonance imaging (MRI) revealed a predominantly cystic

Manuscript submitted March 2, 2019, accepted March 11, 2019

aDepartment of Medicine, Hennepin Healthcare, Minneapolis, MN, USA bepartment of Gastroenterology, University of Minnesota, Minneapolis, MN, USA

'Department of Gastroenterology, Hennepin Healthcare, Minneapolis, MN, USA ${ }^{\mathrm{d} D e p a r t m e n t}$ of Pathology, University of Minnesota, Minneapolis, MN, USA ${ }^{\mathrm{e} C}$ Corresponding Author: Marilia Campos, Department of Medicine, Hennepin Healthcare, 701 Park Ave. (G5), Minneapolis, MN 55415, USA.

Email: Marilia.camposulloa@hcmed.org

doi: https://doi.org/10.14740/gr1170 pancreatic tail mass with irregular walls. The patient underwent an endoscopic ultrasound (EUS) (Fig. 2) the following day, which showed a soft tissue mass with multiple cystic components. Fine-needle aspiration specimen revealed a solid pseudopapillary neoplasm (Fig. 3). The cytopathological (cytomorphologic) study showed small clusters and single cells, few clusters showing a papillary architecture with central fibrovascular core and loosely attached neoplastic cells. Immunostains performed on the cell block showed that tumor cells are positive for beta catenin, Sox-11, CD10, PR and vimentin. He was hospitalized for a total of three nights and had close follow-up in the GI clinic and surgery clinic. Tentative plan is for him to undergo pancreatic resection of the tumor.

\section{Discussion}

SPT represents only about $1 \%$ of all pancreatic tumors and is very rare in young men as in the case presented. Most cases are found in young women (10:1) and the mean age of presentation is 22 years [1]. It is often clinically asymptomatic, as in our patient; however, it can also present with abdominal pain, a gradually enlarging mass, or rarely with jaundice [2]. Most SPTs are benign tumors; however, malignancy can occur in about $15 \%$ of cases, thus surgical resection is recommended $[3,4]$. The most common

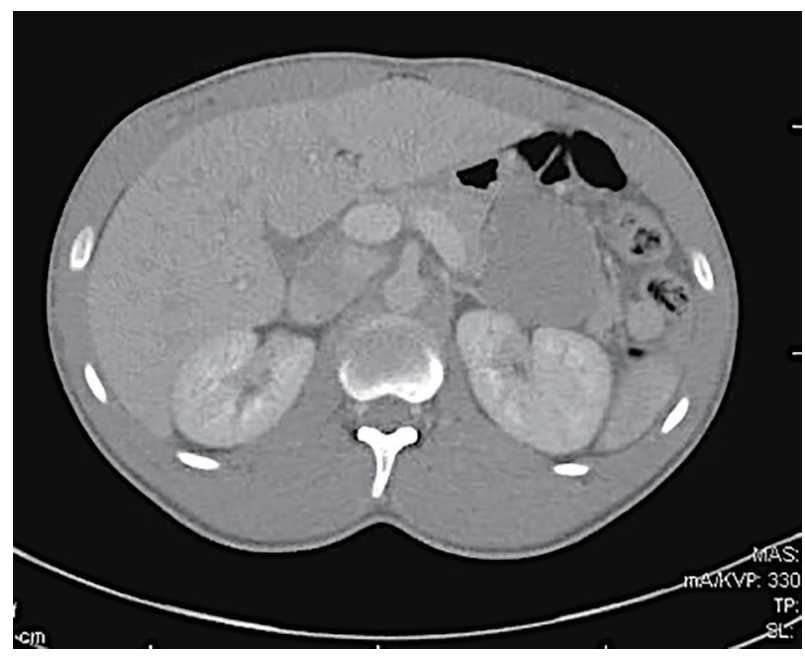

Figure 1. Contrast-enhanced computed tomography evidencing 5.8 $\mathrm{cm}$ pancreatic mass. 


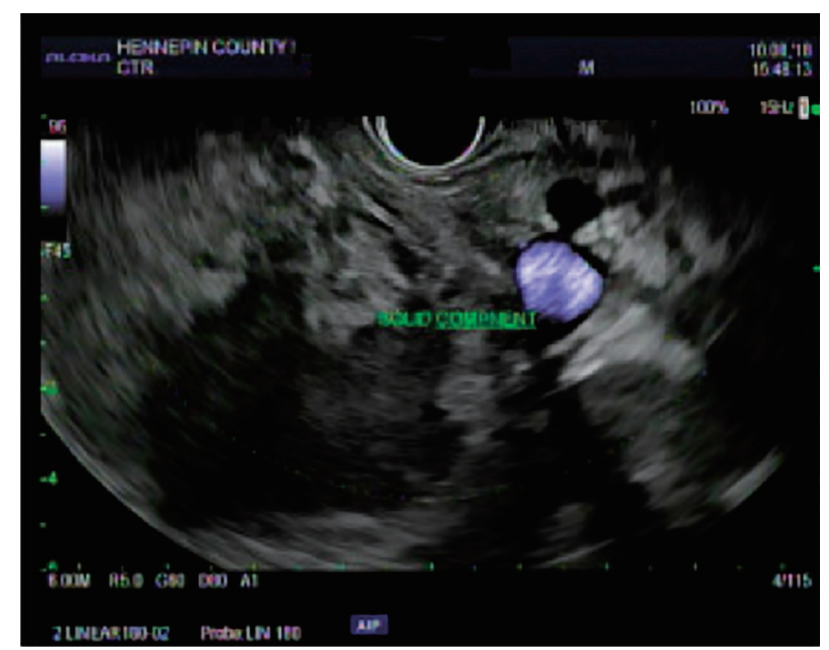

Figure 2. Endoscopic ultrasound (EUS) showing a soft tissue mass with multiple cystic areas.

metastatic sites are liver and omentum, and metastases are more commonly associated with tumors located in the pancreatic body and tail $[3,5]$. SPTs rarely manifest themselves clinically and this case demonstrates how an incidental finding saved this young man's life. The patient will now have an overall 5-year survival of $97 \%$ given he will undergo surgical resection [3].

\section{Acknowledgments}

None to declare.

\section{Financial Disclosure}

None to declare.

\section{Conflict of Interest}

None to declare.

\section{Informed Consent}

Informed consent was obtained from the patient.

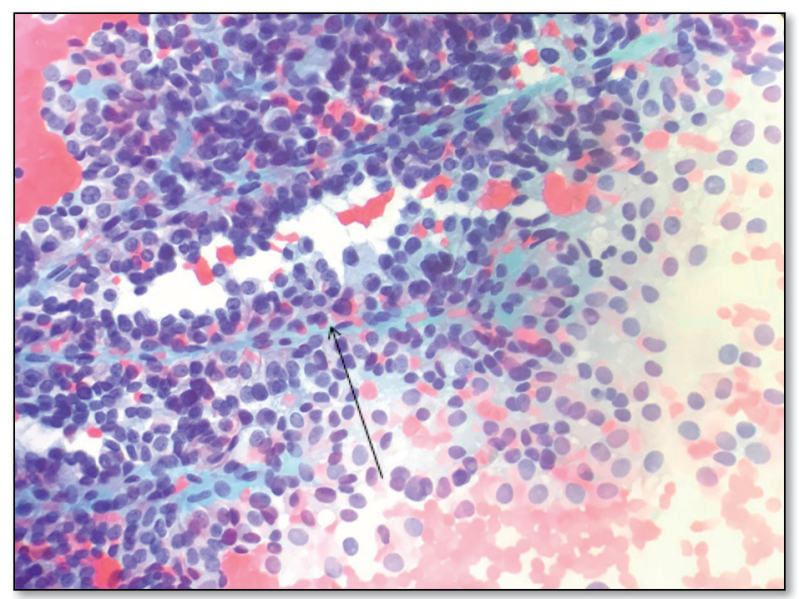

Figure 3. Cytopathological (cytomorphologic) study showing small clusters and single cells, few clusters showing a papillary architecture with central fibrovascular core and loosely attached neoplastic cells.

\section{Author Contributions}

Marilia Campos: main author. James Campbell: reviewer. Hernando Gonzalez: reviewer. Mufaddal Najmuddin: provided with pathology images.

\section{References}

1. Mergener K, Detweiler SE, Traverso LW. Solid pseudopapillary tumor of the pancreas: diagnosis by EUS-guided fine-needle aspiration. Endoscopy. 2003;35(12):10831084.

2. Sun CD, Lee WJ, Choi JS, et al. Solid-pseudopapillary tumours of pancreas: 14 years' experience. ANZ J Surg. 2005;75(8):664-689.

3. Chen X, Zhou GW, Zhou HJ, Peng CH, Li HW. Diagnosis and treatment of solid-pseudopapillary tumors of the pancreas. Hepatobiliary Pancreat Dis Int. 2005;4(3):456-459.

4. Mulkeen AL, Yoo PS, Cha C. Less common neoplasms of the pancreas. World J Gastroenterol. 2006;12(20):31803185.

5. Kim MJ, Choi DW, Choi SH, Heo JS, Sung JY. Surgical treatment of solid pseudopapillary neoplasms of the pancreas and risk factors for malignancy. Br J Surg. 2014;101(10):1266-1271. 